\title{
Lidar and radar measurements of the melting layer: observations of dark and bright band phenomena
}

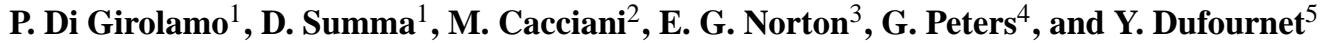 \\ ${ }^{1}$ Dipartimento di Ingegneria e Fisica dell'Ambiente, Università degli Studi della Basilicata, Potenza, Italy \\ ${ }^{2}$ Dipartimento di Fisica, Università degli Studi di Roma "La Sapienza", Roma, Italy \\ ${ }^{3}$ School of Earth, Atmospheric \& Environmental Sciences, University of Manchester, Manchester, UK \\ ${ }^{4}$ Meteorologisches Institut, Universität Hamburg, Hamburg, Germany \\ ${ }^{5}$ Delft University of Technology, Delft, The Netherlands \\ Correspondence to: P. Di Girolamo (paolo.digirolamo@unibas.it)
}

Received: 20 August 2011 - Published in Atmos. Chem. Phys. Discuss.: 21 November 2011

Revised: 12 March 2012 - Accepted: 11 April 2012 - Published: 10 May 2012

\begin{abstract}
Multi-wavelength lidar measurements in the melting layer revealing the presence of dark and bright bands have been performed by the University of BASILicata Raman lidar system (BASIL) during a stratiform rain event. Simultaneously radar measurements have been also performed from the same site by the University of Hamburg cloud radar MIRA $36(35.5 \mathrm{GHz})$, the University of Hamburg dualpolarization micro rain radar $(24.15 \mathrm{GHz})$ and the University of Manchester UHF wind profiler $(1.29 \mathrm{GHz})$. Measurements from BASIL and the radars are illustrated and discussed in this paper for a specific case study on 23 July 2007 during the Convective and Orographically-induced Precipitation Study (COPS). Simulations of the lidar dark and bright band based on the application of concentric/eccentric sphere Lorentz-Mie codes and a melting layer model are also provided. Lidar and radar measurements and model results are also compared with measurements from a disdrometer on ground and a two-dimensional cloud (2DC) probe onboard the ATR42 SAFIRE. Measurements and model results are found to confirm and support the conceptual microphysical/scattering model elaborated by Sassen et al. (2005).
\end{abstract}

\section{Introduction}

Changes in scattering properties of precipitating particles are found to take place during the snowflake-to-raindrop transition in the proximity of the melting level. A maximum in radar reflectivity, known as the radar bright band, is observed in the microwave scattering domain, while a minimum in lidar echoes appears at optical wavelengths, this phenomenon being referred to as lidar dark band (Sassen and Chen, 1995).

The radar bright band has been known and studied for more than three decades and it is presently a well understood phenomenon (Battan, 1973; Meneghini and Liao, 2000), dominated by Rayleigh dielectric scattering effects. As snowflakes descend below the melting level inside the melting layer, their radar reflectivity increases as a result of melting, because the dielectric constant of water exceeds that of ice by a factor of approximately 5 (Rogers and Yau, 1989). Lower in the melting layer, snowflakes collapse into raindrops; since rain drops fall faster than snowflakes, their volume concentration is reduced. This reduction in concentration is the primary cause for decreasing of reflectivity. While the radar bright band is ubiquitous in the $\mathrm{S}, \mathrm{L}, \mathrm{C}$ and $\mathrm{X}$ band (Smith and Illingworth, 1998; Matrosov et al., 2005), only intermittent evidence is found in the $\mathrm{K}$ and $\mathrm{W}$ bands (Sassen et al., 2005), because of the dominance in these latter bands of non-Rayleigh scattering effects.

Observations of the lidar dark band have been reported in a variety of papers (Sassen and Chen, 1995; Demoz et al., 2000; Roy and Bissonnette, 2001; Sassen et al., 2005). Model simulations of this phenomenon have been provided by Di Girolamo et al. (2003), Griaznov et al. (2004) and Sassen et al. (2005). There is a consolidated agreement within the scientific community on the interpretation of what is occurring in the melting layer during the snowflake to raindrop transition process, based on 
the conceptual microphysical/scattering model elaborated by Sassen et al. (2005). Specifically, the lidar dark band is believed to be the result of three conflicting microphysical processes: (a) the structural collapse of partly melted snowflakes, leading to a decrease of lidar backscattering due to the reduced particle size, (b) the progressive removal from the drops center of the embedded ice mass, due to its final melting, thus dampening lidar backscatter associated with the paraxial reflection off the rear face of the droplets, and (c) the completion of the melting process, leading to an increase of lidar backscattering associated with spherical particle backscattering mechanisms coming into prominence (Sassen and Chen, 1995; Sassen et al., 2005).

The lidar dark-band minimum occurs in the melting region, just below (approx. 100-200 m) the radar bright band peak, close to where radar Doppler velocity reaches maximum values. A relative lidar bright band is also present few hundred meters above the dark band in the proximity of the melting level (Sassen, 1977a; Sassen and Chen, 1995; Sassen et al., 2005), associated with the combined occurrence of the increasingly strong snowflake backscattering with height and the pronounced attenuation of the laser beam in the snowfall region, while a weaker bright band located few hundred meters below the dark band has been also conjectured by Di Girolamo et al. (2003), associated with additional scattering processes involving melting hydrometeors.

A comprehensive study of the dark and bright band phenomena both in terms of measurements and model representation has been published by Sassen et al. (2005), where the authors report measurements performed by a singlewavelength $(523 \mathrm{~nm})$ backscatter lidar system (Sassen et al., 2003) and a three-wavelength Doppler radar (0.32-, 0.86-, and $10.6 \mathrm{~cm}$ ). Unfortunately, in the observations reported by Sassen et al. (2005) lidar and radar depolarization and in-situ drop size measurements, which would have provided further information on the state of the melting particles, were not available from the instruments involved. Recently, however, lidar and radar depolarization measurements of melting particles, in combination with three-wavelength radar reflectivity and Doppler velocity measurements $[0.84 \mathrm{~cm}(35.5 \mathrm{GHz})$, $1.24 \mathrm{~cm}(24.15 \mathrm{GHz})$ and $23.24 \mathrm{~cm}(1.129 \mathrm{GHz})]$, with threewavelength lidar backscatter measurements $(355,532$ and $1064 \mathrm{~nm}$ ) and in-situ measurements from a two-dimensional cloud probe, have been carried out in the frame of COPS. These data are reported in the present paper, focusing on a case study revealing the presence of the full repertoire of lidar/radar dark/bright band phenomena. Specifically, the availability of lidar measurements of the dark and bright bands at different wavelengths reveal the presence of wavelength dependent feature in the optical domain, which could not be considered in previous studies. The present measurements were carried out in very light precipitation (rainfall rate was $0.02-0.05 \mathrm{~mm} \mathrm{~h}^{-1}$ ), which represent an interesting case study integrating the measurement conditions reported by Sassen et al. (2005), characterized by higher intensity rain showers $\left(0.07-1.52 \mathrm{~mm} \mathrm{~h}^{-1}\right)$.

Simulations of the lidar dark and bright band are provided based on application of concentric/eccentric sphere LorentzMie scattering codes and a melting layer model. In these scattering models, melting hydrometeors are modelled as twolayered concentric/eccentric sphere particles, consisting of a water shell around an inner core of snow or ice. Simulations highlight backscattering enhancements, which are associated with the predominance of spherical particle backscatter mechanisms. These enhancements play a major role in the lidar dark/bright band phenomena observed in the melting layer, as clearly implied in the conceptual model proposed by Sassen et al. (2005). The present paper combines scattering model results with results from a melting layer model to quantify the range from the melting level at which the scattering phenomena are expected to take place.

Lidar and radar measurements and model results are also compared with measurements from a disdrometer on ground and a two-dimensional cloud (2DC) probe on-board a scientific research aircraft. Measurements and model simulations illustrated and discussed in this paper provide additional experimental evidence and model verification of the lidar/radar dark/bright bands that support the microphysical/scattering interpretation of these phenomena provided by Sassen et al. (2005).

\section{Lidar and radar systems}

The measurements illustrated in this paper were performed in the framework of COPS held in Southern Germany and Eastern France in the period 1 June-31 August 2007 (Wulfmeyer et al., 2008; Richard et al., 2009). COPS was conceived with the primary goal of advancing the quality of forecasts of orographically induced convective precipitation by four-dimensional observations and modeling of its life cycle (Kottmeier et al., 2008; Kalthoff et al., 2009; Wulfmeyer et al., 2011). As part of COPS, a transect of five Supersites, equipped with advanced in-situ and remote sensing instrumentation, was set up from the Vosges Mountains (supersite V) to the lee side of the Black Forest close to Stuttgart (supersite S), crossing the Rhine valley (supersite R), the Hornisgrinde Mountain (supersite H) and the Murg Valley (supersite M).

The University of BASILicata Raman lidar system $(B A S I L)$ was deployed throughout the duration of COPS in Supersite R (Achern, Rhine Valley, Lat: $48.64^{\circ} \mathrm{N}$, Long: $8.06^{\circ} \mathrm{E}$, Elev.: $140 \mathrm{~m}$ ). The system operated between 25 May and 30 August 2007 and collected more than 500 hours of measurements, distributed over 58 measurement days (examples of measurements of BASIL from this field deployment are given in Behrendt et al., 2011; Chaboureau et al., 2011; Bennett et al., 2011; Corsmeier et al., 2011; Kiemle et al. 2011; Di Girolamo et al., 
Table 1. Specifications of the Raman lidar and the three radars deployed in Achern during the Convective and Orographically-induced Precipitation Study.

\begin{tabular}{lllll}
\hline & BASIL & MIRA 36 & Univ. of Hamburg rain radar & Univ. of Manchester wind profiler \\
\hline Band & UV, vis., IR & Ka-band & K-band & UHF-band \\
Frequency & $840,560,280 \mathrm{THz}$ & $35.5 \mathrm{GHz}$ & $24.15 \mathrm{GHz}$ & $1.29 \mathrm{GHz}$ \\
Wavelength & $355,532,1064 \mathrm{~nm}$ & $0.84 \mathrm{~cm}$ & $1.24 \mathrm{~cm}$ & $23.24 \mathrm{~cm}$ \\
Power & $6-8 \mathrm{~W}$ (average) & $30 \mathrm{~kW}$ (peak) & $50 \mathrm{~mW}$ & $3.5 \mathrm{~kW}$ (peak), $100 \mathrm{~W}($ average) \\
Pulse repetition frequency & $20 \mathrm{~Hz}$ & $10 \mathrm{kHz}$ & $1953 \mathrm{kHz}$ (sweep rate) & $10 \mathrm{kHz}$ \\
Range resolution (m) & $15-30 \mathrm{~m}$ & 30 & 100 & $75-375$ \\
Time resolution (s) & $5-60$ & 10 & 10 & 120 \\
\hline
\end{tabular}

2012). Quicklooks of the data are visible on the COPS Website (http://www.cops2007.de/), under Operational Products, while the data can be downloaded from the World Data Center for Climate (http://cera-www.dkrz.de/WDCC/ ui/BrowseExperiments.jsp?proj=COPS) or, alternatively, can be requested to the authors.

The major feature of BASIL is its capability to perform high-resolution measurements of atmospheric temperature and water vapour, both in daytime and night-time, based on the application of the rotational and vibrational Raman lidar techniques in the ultraviolet (UV) (Di Girolamo et al., 2004; Di Girolamo et al., 2006, 2009a; Bhawar et al., 2011). Besides temperature and water vapour, BASIL measures particle backscatter at 355, 532 and $1064 \mathrm{~nm}$, particle extinction coefficient at 355 and $532 \mathrm{~nm}$ and particle linear depolarization at 355 and $532 \mathrm{~nm}$ (Maestri et al., 2010; Griaznov et al., 2007; Di Girolamo et al., 1996, 2009b). BASIL is not protected from precipitation and therefore cannot be operated when rain reaches the ground. However, a careful and conservative operation of the system till shortly before precipitation reaches the ground allowed us to capture several episodes involving melting hydrometeors.

During COPS, BASIL was co-located with the University of Hamburg cloud radar MIRA $36(35.5 \mathrm{GHz}, 0.84 \mathrm{~cm}$, Kaband), the University of Hamburg dual-polarization micro rain radar $(24.15 \mathrm{GHz}, 1.24 \mathrm{~cm}, \mathrm{~K}$-band) and the University of Manchester UHF wind profiler $(1.29 \mathrm{GHz}, 23.24 \mathrm{~cm}$, UHF band) (Norton et al., 2006). The main specifications of the lidar and radars are provided in Table 1 . The three zenithpointing radars represent a unique combination of microwave sensors. Atmospheric probing at the shortest wavelengths $(0.84$ and $1.24 \mathrm{~cm})$ is relatively sensitive to cloud droplets and some ice crystals (Sassen et al., 2005; Lhermitte, 1988). In contrast to the K- and Ka-band radars, the UHF radar $(23.24 \mathrm{~cm})$ cannot generally observe particles suspended in a cloud, but rather observes larger precipitation particles, whose return signals can be treated relatively simply with Rayleigh scattering theory (Kiran Kumar et al., 2006).

Ancillary information on the state of the atmosphere was provided by radiosondes, launched every three hours during each measurement session, as well as by a sodar and a mi-

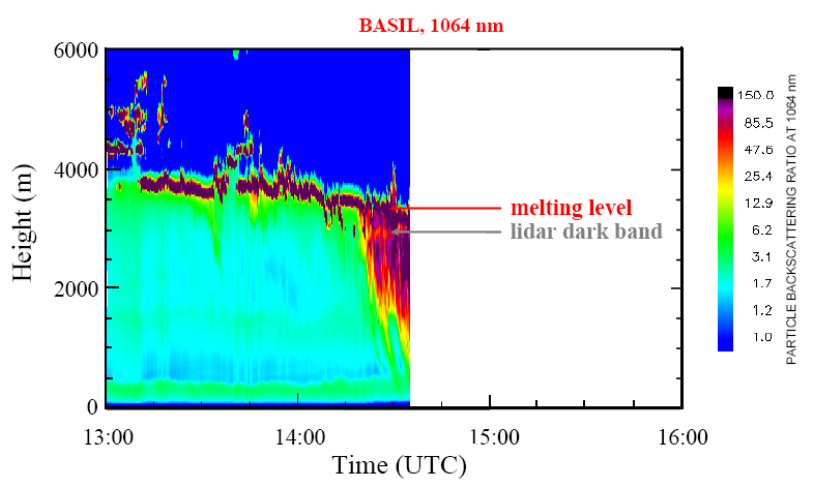

Fig. 1. Time evolution of the particle backscatter ratio at $1064 \mathrm{~nm}$ from 13:00 UTC to 14:35 UTC on 23 July 2007 as measured by the Raman Lidar system BASIL. Arrows highlight the location of the melting level and the lidar dark band.

crowave radiometer. Additional information on precipitating hydrometeors were obtained from a disdrometer, located in Besenfeld, $27 \mathrm{~km}$ East of Supersite R, and a two-dimensional cloud (2DC) probe (Appendix A), hosted on-board the scientifically equipped aircraft ATR42 from Service des Avions Français Instrumentés pour la Recherche en Environnement (SAFIRE). This large "ensemble" of instruments makes the collected dataset very useful for the purpose of studying precipitating hydrometeors in the melting layer.

\section{Results}

\subsection{Lidar and radar measurements}

Lidar dark and bright bands were observed by BASIL during several intensive observation periods (among others, on 23 July, 15 August, and 17 August 2007). However, for the purpose of this paper we focused our attention on the measurements performed on 23 July 2007. A forthcoming paper will focus on extending the analysis to the complete set of dark/bright band cases.

Figure 1 illustrates the time evolution of BASIL measurements of the particle backscatter ratio (Di Girolamo et al., 
1999) at $1064 \mathrm{~nm}$ from 13:00 UTC to $16: 00$ UTC on 23 July 2007. The particle backscatter ratio, defined as the ratio of the particle backscattering coefficient over the molecular backscattering coefficient, is a parameter that quantifies cloud/hydrometeor loading, dependent on both their size and density. The figure reveals the presence of stratiform clouds, with cloud base at $3.4-3.8 \mathrm{~km}$ above ground level (a.g.l.). Around 14:15 UTC, hydrometeors start precipitating from the clouds.

On 23 July 2007, the COPS region was affected by a cyclonic system that developed over the eastern North Atlantic and approached the area in the evening. Ahead of this system, midlevel stratiform clouds reached the COPS region in the afternoon and stratiform rainfall events occurred. These conditions are more favourable for the observation of radar and lidar melting-layer phenomena than in the presence of strong thunderstorms, as in fact in this latter case radar and lidar signals may be overwhelmed by the strong hydrometeors echoes. Dark/bright lidar bands are more easily observed in the presence of relatively light precipitation events, with the signal throughout the melting layer not being significantly attenuated by the rain droplets. The present measurements were carried out in very light precipitation conditions (rainfall rate was $0.02-0.05 \mathrm{~mm} \mathrm{~h}^{-1}$ as measured by the disdrometer located in Besenfeld).

The melting level, that is the $0{ }^{\circ} \mathrm{C}$ isotherm level, identified through the radiosonde launched at 14:06 UTC, was located at $3.35 \mathrm{~km}$ a.g.l. (red arrow in Fig. 1; the temperature profile from this radiosonde is illustrated in Fig. 7). Although we show in this and the following figures the position of the melting level based on the use of the radiosounding, precipitation processes can significantly alter the local atmospheric structure, with the temperature gradient in the melting layer varying as a result of evaporative cooling and vertical motion (Stewart et al., 1984). According to Mitra et al. (1990), as a result of sublimation cooling effects, sub-saturated air delays the onset of snowflake melting by approximately $100 \mathrm{~m}$ for each $10 \%$ of sub-saturation. The radiosonde launched at 14:06 indicates a relative humidity value at the melting level of $90 \%$. Thus, start of significant melting is expected to be delayed down to a height of $3.25 \mathrm{~km}$ a.g.l.

The dark band appears in Fig. 1 as a shallow layer of relatively smaller particle backscatter values, located at 2.8 $2.9 \mathrm{~km}$ a.g.l. between 14:15 and 14:35 UTC (gray arrow in the figure). More specifically, values of the particle backscatter ratio at this altitude are $\sim 2$ times smaller that those found a few hundred meters below (weak lidar bright band) and up to a factor of 10 smaller than those found higher up in the proximity of the melting level and cloud base (strong lidar bright band). Lidar measurements were stopped at 14:35 UTC because of the rain reaching the surface and entering the telescope.

Evidence of a radar bright band is found in measurements from the three zenith-pointing radars present on site. Figure 2 shows the evolution with time of radar reflectivity at

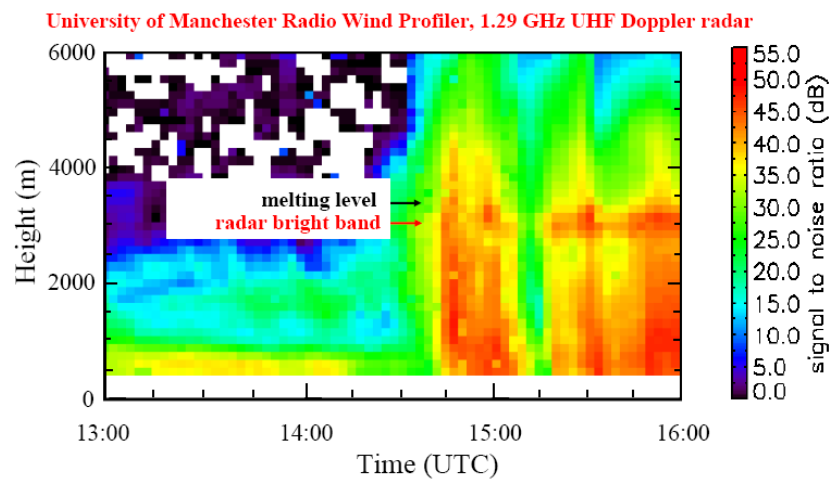

Fig. 2. Time evolution of radar reflectivity at $1.29 \mathrm{GHz}$ from 13:00 UTC to 16:00 UTC on 23 July 2007 as measured by the clear air wind profiler. Arrows indicate the location of the melting level and the radar bright band.

$1.29 \mathrm{GHz}$ (expressed in $\mathrm{dB}$ ) as measured by the University of Manchester wind profiler from 13:00 UTC to 16:00 UTC. The radar bright band peak (red arrow in Fig. 2) occurs in the melting region at $\sim 3.0 \mathrm{~km}$ a.g.l., just above $(100-200 \mathrm{~m})$ the lidar dark-band minima.

Figure 3 shows the time evolution of the radar reflectivity at $35.5 \mathrm{GHz}$ from 13:00 UTC to 16:00 UTC as measured by MIRA 36. Again, the radar bright band appears as a reflectivity peak around $3.0 \mathrm{~km}$ a.g.l. (red arrow in the figure). However, the maximum is less marked than at $1.29 \mathrm{GHz}$. In this regard, we recall that the radar bright band is always visible in the $\mathrm{X}$ band and longer wavelengths, while it is intermittently found at shorter wavelengths (Sassen et al., 2005), because of the dominance of non-Rayleigh scattering effects in large water-coated snowflakes precipitating throughout the melting layer. Figure 4 shows the time evolution of the radar reflectivity at $24.15 \mathrm{GHz}$ for the time interval from 13:00 UTC to 16:00 UTC as measured by the micro rain radar. Again, the radar bright band appears as a reflectivity peak around $3.0 \mathrm{~km}$ a.g.l. (red arrow in the figure).

Figure 5 illustrates the time evolution of the linear depolarization ratio at $35.5 \mathrm{GHz}$ from 13:00 UTC to 16:00 UTC as measured by MIRA 36. The figure reveals the presence of enhanced depolarization values in the bright band layer, where linear depolarization ratio values reach $-10 \mathrm{~dB}$. Radar depolarization is commonly increased due to the presence of wetted, asymmetric ice shapes (Sassen and Chen, 1995). To complement enhanced radar reflectivity and increased depolarization, an abrupt change in Doppler-derived particle velocities at $35.5 \mathrm{GHz}$ is also found in the melting layer (Fig. 6), as a result of the melting process leading to smaller particles with more regular shapes and smaller impact area. Values of Doppler vertical velocity do not exceed $2-3 \mathrm{~m} \mathrm{~s}^{-1}$ above and in the upper part of the melting layer, while larger values $\left(>4 \mathrm{~m} \mathrm{~s}^{-1}\right)$ appear in the lower portion of the melting layer.

Figure 7 illustrates the lidar and radar data expressed in terms of averaged vertical profiles, together with ancillary 


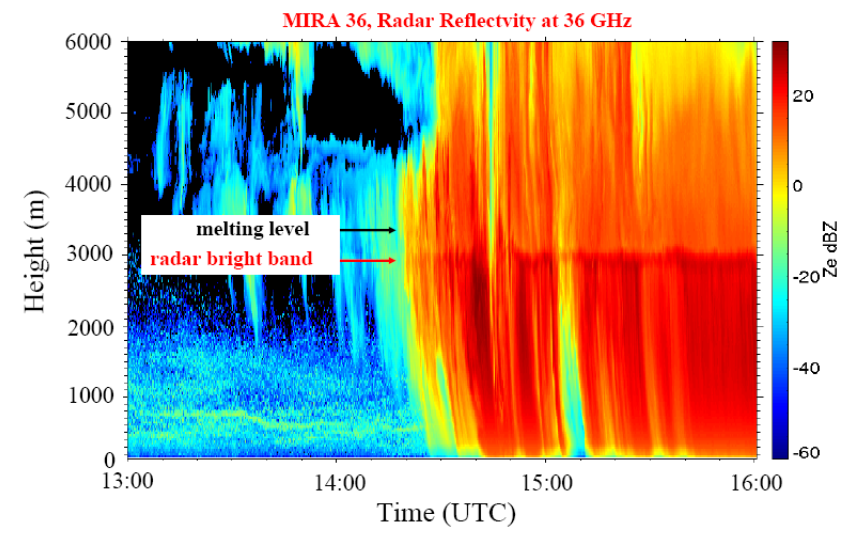

Fig. 3. Time evolution of radar reflectivity at $35.5 \mathrm{GHz}$ from 13:00 UTC to 16:00 UTC on 23 July 2007 as measured by MIRA 36. Arrows indicate the location of the melting level and the radar bright band.

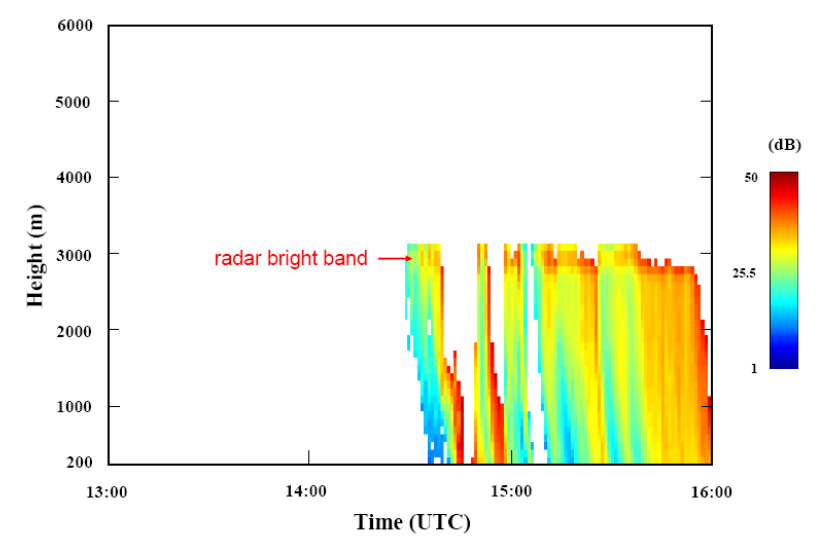

Fig. 4. Time evolution of radar reflectivity at $24.15 \mathrm{GHz}$ from 13:00 UTC to 16:00 UTC on 23 July 2007 as measured by the micro rain radar. The red arrow indicates the location of the radar bright band.

information from the radiosonde data. Specifically, panel a shows the vertical profile of temperature at 14:06 UTC, revealing the height of the melting level at $\sim 3.35 \mathrm{~km}$ a.g.l. Panel $\mathrm{b}$ shows the vertical profiles of the radar reflectivity at $35.5 \mathrm{GHz}(0.84 \mathrm{~cm}), 24.15 \mathrm{GHz}(1.24 \mathrm{~cm})$ and $1.29 \mathrm{GHz}$ $(23.24 \mathrm{~cm})$, revealing the presence at all wavelengths of the radar bright band (appearing as a reflectivity maximum) at $2.9-3.0 \mathrm{~km}$ a.g.1., or $350-450 \mathrm{~m}$ below the melting level at a temperature of $3.4-4.4^{\circ} \mathrm{C}$. Radar profiles in this and the other panels are based on $12 \mathrm{~min}$ data averaging over the time interval 14:23-14:35 UTC. Panel c shows the vertical profiles of the backscattering coefficient at 355, 532 and $1064 \mathrm{~nm}$, highlighting the presence of a strong bright band (marked backscatter maximum) in the proximity of the melting level (at $3.4 \mathrm{~km}$ a.g.l.) and of a dark band (backscattering minimum) at approximately $2.9 \mathrm{~km}$ a.g.1., or $450 \mathrm{~m}$ below the melting level at a temperature of $4.4^{\circ} \mathrm{C}$. A weaker

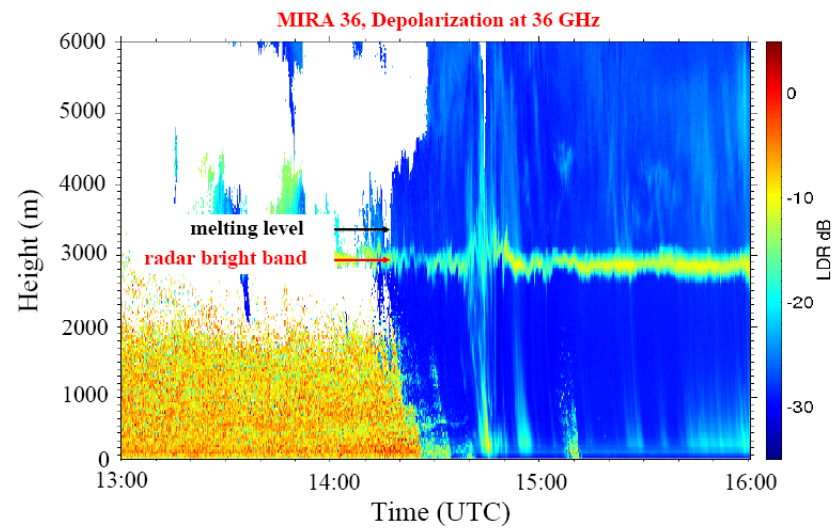

Fig. 5. Time evolution of the linear depolarization ratio at $35.5 \mathrm{GHz}$ from 13:00 UTC to $16: 00$ UTC on 23 July 2007 as measured by MIRA 36. Arrows indicate the location of the melting level and the radar bright band.

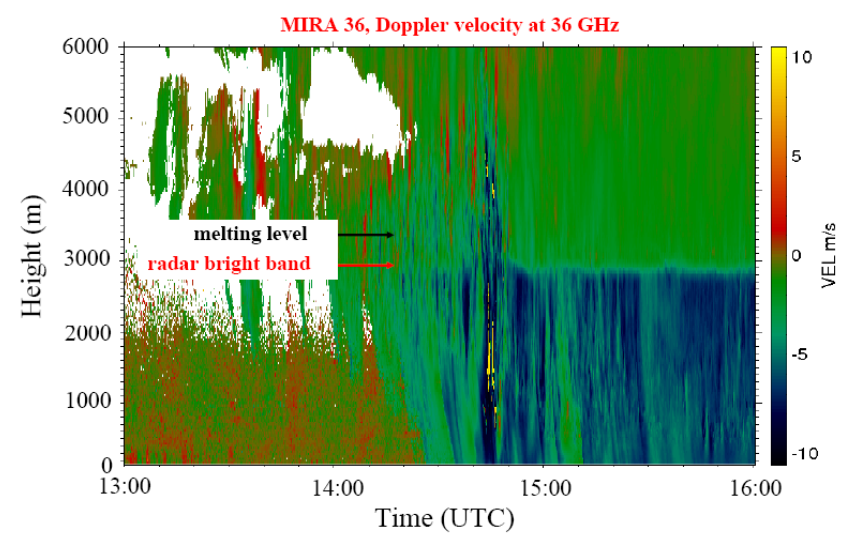

Fig. 6. Time evolution of hydrometeors vertical velocity from 13:00 UTC to 16:00 UTC on 23 July 2007 as measured by MIRA 36. Arrows indicate the location of the melting level and the radar bright band.

bright band is found approximately $100-200 \mathrm{~m}$ further down at $2.7-2.8 \mathrm{~km}$ a.g.1. Lidar profiles in this panel and in panel e are based on 15 minute data averaging over the time interval 14:20-14:35 UTC.

The presence of a lidar dark band has been reported and extensively discussed in previous papers (e.g. Sassen and Chen, 1995; Demoz et al., 2000; Sassen et al., 2005). Specifically, for the case study reported by Sassen and Chen (1995) the dark band appears $\sim 750 \mathrm{~m}$ below the melting level. For the case study reported by Demoz et al. (2000) the dark band appears $150-300 \mathrm{~m}$ below the melting level. For the three case studies reported by Sassen et al. (2005) the dark band appears 200-700 $\mathrm{m}$ below the melting level, with smaller distances of the dark band from the melting level observed in the cases characterized by low precipitation rates.

Concerning the strong bright band, this is observed in the backscattering coefficient profiles at 532 and $1064 \mathrm{~nm}$ 
23 July 2007
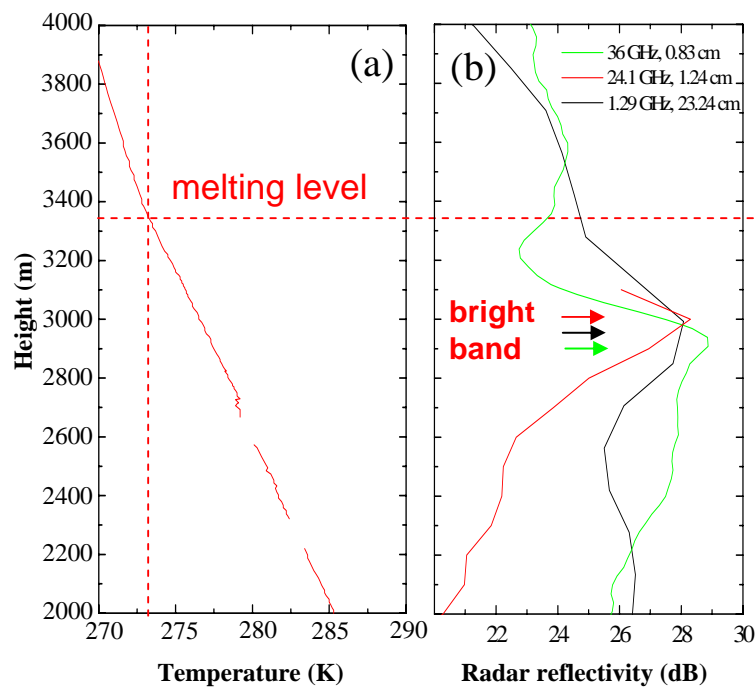

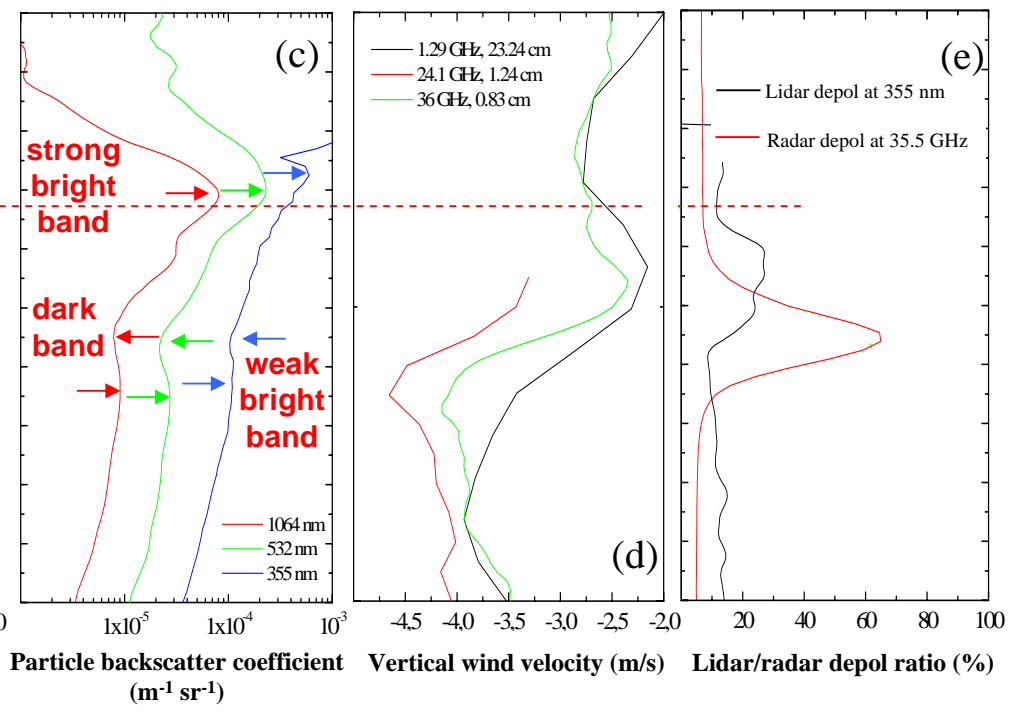

Fig. 7. Vertical profile of temperature as measured by the radiosonde launched at 14:06 UTC (a); vertical profile of radar reflectivity at 35.5 GHz, 24.15 GHz and 1.29 GHz (b, data are averaged over the time interval 14:23-14:35 UTC); vertical profile of backscattering coefficient at 355, 532 and $1064 \mathrm{~nm}$ (c, data averaged over the time interval 14:20-14:35 UTC); vertical profile of vertical velocity measured at $35.5 \mathrm{GHz}$ and $1.29 \mathrm{GHz}$ (d, data averaged over the time interval 14.23-14:35 UTC); lidar (at $355 \mathrm{~nm}$ ) and radar (at $35.5 \mathrm{GHz}$ ) depolarization (e, lidar data averaged over the time interval 14:20-14:35 UTC, radar data averaged over the time interval 14:23-14:35 UTC). In panel a the range of radar reflectivities has been compressed by subtracting $15 \mathrm{dBZ}$ to the $1.29 \mathrm{GHz}$ data.

slightly above the melting level (at $3.4 \mathrm{~km}$ a.g.l.) and owes its existence to the increasingly strong snowflake backscattering with height coupled with the overwhelming attenuation rate in the snowfall embedded within the cloud base. The presence of this stronger bright band was reported and discussed by Sassen (1977a), Sassen and Chen (1995) and Sassen et al. (2005). It is to be noticed that this bright band phenomenon may appear at different altitudes depending on the wavelength and energy of the laser beam which gets attenuated by the snow. In the present case, the maximum in the particle backscatter coefficient at $355 \mathrm{~nm}$ (blue line in panel c) is less marked and appears at a higher altitude than the one observed at 532 and $1064 \mathrm{~nm}$ (green and red lines in panel c).

Concerning the weak lidar bright band found in the melting layer $100-200 \mathrm{~m}$ below the bright band, we specify that similar features were also present in the aerosol scattering ratio measurements reported by Demoz et al. (2000), with maxima $300 \mathrm{~m}$ below the dark band height, and in the lidar return echoes reported by Sassen et al. (2005) for the two case studies characterized by light intensity rain showers $(0.07$ and $0.09 \mathrm{~mm} \mathrm{~h}^{-1}$ ), with maxima appearing $500-600 \mathrm{~m}$ below the dark band height. However, in the present data set the weak bright band appears at an height closer to the dark band (only 100-200 m below) and has a smaller vertical extent with respect to that reported by Sassen et al. (2005). This is probably the result of the lower precipitation rate and smaller melting hydrometeor sizes charactering the present case study, in combination with raindrop evaporation mechanisms. It is to be pointed out that the backscattering profiles illustrated in panel c of Fig. 7 show a very limited wavelength dependence of the dark and weak bright band features, not unexpectedly indicating that the particles profiled are much larger than the sounding wavelength and behave as geometric optics scatters.

Panel d shows the profile of vertical velocity, as measured at $35.5 \mathrm{GHz}, 24.15 \mathrm{GHz}$ and $1.29 \mathrm{GHz}$. Values at $35.5 \mathrm{GHz}$ and $1.29 \mathrm{GHz}$ are $2-2.5 \mathrm{~m} \mathrm{~s}^{-1}$ in the upper melting layer and $3.5-4 \mathrm{~m} \mathrm{~s}^{-1}$ in the lower portion of the melting layer. Values measured by the rain radar at $24.15 \mathrm{GHz}$ are slightly larger in the upper melting layer (as large as $3.5 \mathrm{~m} \mathrm{~s}^{-1}$ ) and in the lower portion of the melting layer (as large as $4-4.5 \mathrm{~m} \mathrm{~s}^{-1}$ ), probably as a result of the higher sensitivity of the $24.15 \mathrm{GHz}$ band to larger and consequently faster particles. Doppler velocity profiles at the three wavelengths are weighted toward different portions of the particle size distribution (Sassen et al., 2005).

Lidar (at $355 \mathrm{~nm}$ ) and radar (at $35.5 \mathrm{GHz}, 0.84 \mathrm{~cm}$ ) depolarization profiles are shown in panel e of Fig. 7. Enhanced radar reflectivity and depolarization values and an abrupt change in Doppler-derived particle velocities are found in the melting layer, which depict the presence of the radar bright band. Radar depolarization at the height of the radar bright band is as large as $60 \%$ due to the presence of wetted snowflakes just before they collapse into raindrops. In contrast to this, lidar depolarization at $355 \mathrm{~nm}$ shows values 
of $25-30 \%$ high in the melting layer and values of 5-10\% at the heights of the lidar dark band and weak bright band. The presence of large depolarization values high in the melting layer testifies to the predominant presence of irregular shape snowflakes (Sassen, 1975; Sassen, 1977b), while the low values at the heights of the lidar dark and weak bright band suggest the presence of severely melted snowflakes that have collapsed into mixed phase particles and have a more regular shape, confirming the microphysical and scattering conceptual model proposed by Sassen et al. (2005). Similarly low lidar depolarization values $(3 \%)$ were also reported at the height of the lidar dark band by Sassen and Chen (1995).

\subsection{Model simulations}

The purpose of this section is to describe model simulations of the observed lidar backscatter measurements in support of microphysical and scattering conceptual model of melting hydrometers and lidar/radar dark/bright band phenomena interpretation proposed by Sassen et al. (2005). Computations of the scattering properties of the melting hydrometeors and simulations of the lidar dark and bright bands are performed based on the application of concentric/eccentric sphere Lorentz-Mie codes and a melting layer model.

Melting hydrometeors are frequently modelled as a twolayered concentric/eccentric sphere particles, consisting of a water shell sourrounding an inner core of snow or ice (e.g., Aydin and Zhao, 1990; Prodi et al., 1996; Fabry and Szyrmer, 1999; Meneghini and Liao, 2000). This approach has been considered primarily to represent precipitating hailstones, graupel and melting snowflakes (Yokoyama and Tanaka, 1984; Mitra et al., 1990; Fabry and Szyrmer, 1999). The concentric/eccentric water/ice sphere model may also reasonably apply to conditions in the initial melting process (Sassen et al., 2005), when melting snowflakes consist of myriad water coatings and irregular drop beads. In the present computations we consider a log-normal size distribution for the melting hydrometeors with parameters taken from Willis (1984, number concentration $N=10^{3} \mathrm{~m}^{-3}$, mode radius $r_{s}=1.5 \mathrm{~mm}$, width $\sigma=1.7$ ).

Figure 8a illustrates the variability of the volume backscattering coefficient at $350 \mathrm{~nm}$ as a function of the melting ratio (i.e. the core/shell radius ratio, $r_{c} / r_{s}$ ) as simulated through the application of the concentric sphere code (Aden and Kerker, 1951, Toon and Ackerman; 1981). Simulations in the optical domain $(350 \mathrm{~nm})$ for hydrometeors with a radius of $1.5 \mathrm{~mm}$ imply particle size parameter values (i.e., the ratio of the particle circumference over the sounding wavelength) in excess of 25000 (Di Girolamo et al., 2003). This imposes long computation times and a careful check for numerical stability. Refractive indexes at $350 \mathrm{~nm}$ for water and ice are taken from Irvine and Pollack (1968).

The figure reveals the presence of an abrupt increase of the volume backscattering coefficient for melting ratio values $r_{c} / r_{s}$ of $0.6-0.8$, which is to be attributed to the major role played in the backscatter process of severely melted hydrometeors by rays with large impact factors and by spherical particle backscattering mechanisms. As mentioned above, the present results are for a mode radius of $1.5 \mathrm{~mm}$, but similar results are also found for smaller and larger radii. An extensive study in this direction was performed by Griaznov et al. (2004). This enhancement in lidar backscattering was also conjectured by Sassen et al. (2005), who ascribe it to mixedphase raindrops benefitting from spherical particle backscattering mechanisms; namely, surface waves and front-face axial reflection, aided by the removal from the drops center of the embedded ice mass as a result of melting and/or internal drop circulations (Pruppacher and Beard 1970). The backscattering enhancement resulting from our scattering model and conjectured by Sassen et al. (2005) is probably playing an important role in the determination of the weak backscatter maximum (weak lidar bright band) which is observed in Fig. 7 100-200 m below the lidar dark band.

A melting model (Yokoyama and Tanaka, 1984) was considered to compute the variability of $r_{c} / r_{s}$ and the melting hydrometeors fall velocities as a function of the range below the $0{ }^{\circ} \mathrm{C}$ isotherm. This model assumes that (a) melting frozen drops are spherical and evenly covered with melted water, (b) precipitation rate is constant and steady at any level, (c) lapse rate of temperature is constant $\left(8^{\circ} \mathrm{C} \mathrm{km}^{-1}\right.$, as resulting from the radiosonde profile illustrated in Fig. 7) and (d) the atmosphere is saturated with water vapour. The model also assumes mass conservation through the melting stages, as well as the heat budget equation proposed by Wexler (1955). In this simplified model coalescence and breakup are completely ignored. A similar melting model was considered by Sassen et al. (2007).

Ranges below the melting level solved from this model are reported on the right scale of both panels of Fig. 8, with results for two different melting particle radii (1.5 and $3.0 \mathrm{~mm}$ ). From these results we realize that the backscattering enhancement generated by the scattering model for $r_{c} / r_{s}$ values of $0.6-0.8$ takes place approximately $250-340 \mathrm{~m}$ below the melting level for $1.5 \mathrm{~mm}$ radius hydrometeors and 400 $580 \mathrm{~m}$ below the melting level for $3.0 \mathrm{~mm}$ radius hydrometeors. Thus, the increase in lidar backscattering revealed by the concentric sphere scattering model is identified by the melting model to take place at a range below the melting level which is comparable to the range below the melting level of the weak backscattering maximum $(550-650 \mathrm{~m})$ observed in the lidar profiles of Fig. 7c. As already mentioned in the measurements section, the distance of these maxima from the melting level and the vertical extent of this bright band are strongly dependent on the hydrometeor size and precipitation rate, but also on the presence of particle evaporation/sublimation mechanisms.

In a simplified representation of melting hydrometeors consisting of an ice core surrounded by a water shell, the severely melted ice core can move to the top or bottom of the drop (Pruppacher and Beard, 1970; Rasmussen et al., 1984). 

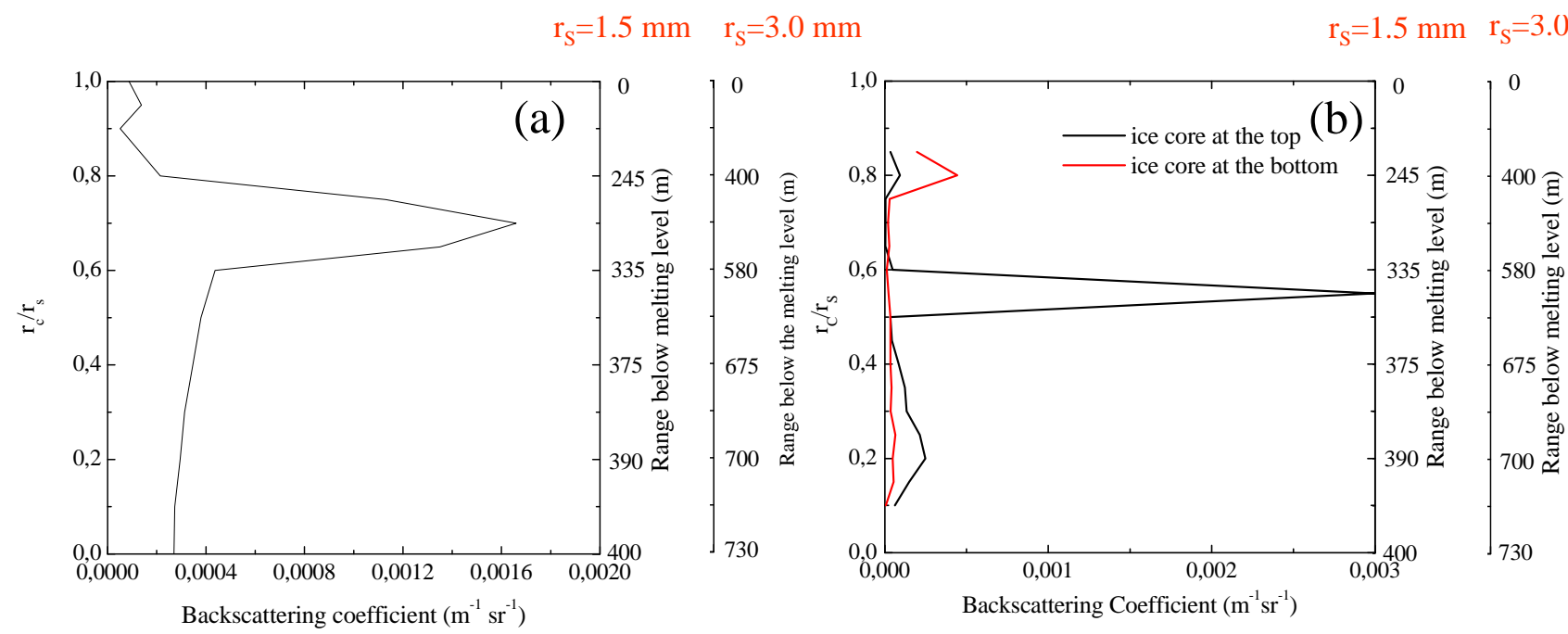

Fig. 8. Volume backscattering coefficient at $350 \mathrm{~nm}$ vs. melting ratio $r_{c} / r_{s}$. (a) shows the results obtained with the concentric sphere model, while (b) shows the results obtained with the eccentric sphere model, with the black line indicating the simulation for the hydrometeor with the ice core at the top of the water shall and the red line the hydrometeor with the ice core at the bottom of the water shall.
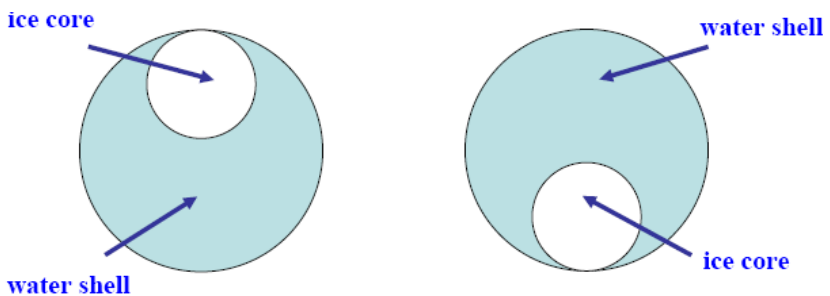

Fig. 9. Schematics of off-centre inclusion particles, with the ice core at the top or bottom of the water shell.

Specifically, the core can float to the top of the water drop if it has entrapped air bubbles or can flutter around inside the drop due to drag-induced internal circulations (Pruppacher and Beard, 1970). So, we also consider a Mie code for large particles with off-centre inclusions, with the ice core at the top or bottom of the water shell (Fig. 9). The code is capable of dealing with size parameter values up to $\sim 1000$.

Figure $8 \mathrm{~b}$ illustrates the variability of the volume backscattering coefficent at $350 \mathrm{~nm}$ as a function of the melting ratio for eccentric sphere particles, with the ice core at the top (black line) and bottom (red line) of the water shell. Results are obtained with a size parameter $x=600$, which corresponds to a hydrometeor radius of $35 \mu \mathrm{m}$. A strong enhancement in backscatter coefficient is observed for a melting ratio of 0.55 , when the ice core is at the top of the water shell, and for a melting ratio of 0.8 when the ice core is at the bottom of the water shell. These results are in general agreement with those obtained with the concentric sphere code. Considering the ranges below the melting level obtained from the above mentioned melting model, we realize that the backscattering maxima observed for melting ratios of 0.55 and 0.8 take place $250-350 \mathrm{~m}$ below the melting level for hydrometeors with a radius of $1.5 \mathrm{~mm}$ and $400-600 \mathrm{~m}$ below the melting level for hydrometeors with a radius of $3.0 \mathrm{~mm}$; these ranges being once again comparable to the range below the melting level of the weak backscattering maximum $(550-650 \mathrm{~m})$ observed in the lidar profiles illustrated in Fig. 7c.

Concentric-eccentric sphere models are a simplified representation of melting snowfalkes, hailstones and graupel, as in fact these types of precipitating particles are a non-spherical mix of ice, water and air. This configuration is very difficult to model exactly. Thus, the results illustrated in the present section are intended to be indicative of the scattering behaviour of melting hydrometeors. A more realistic approach would consist in the application of a Monte Carlo ray-tracing model based on geometrical optics methods. This approach considers particles with very irregular shapes and with a variety of inclusions. However, it may fail for large particle sizes as in the case of precipitating hydrometeors because of its inability to treat circumferentially backscattered surface waves (Sassen, 1977b) and its inability to properly reproduce resonance phenomena. Thus, an accurate model simulation of the scattering properties of melting snowflakes, as well as of the lidar dark/bright band phenomena, is presently an open problem.

\subsection{DC probe, rain radar and disdrometer measurements}

Additional information on the precipitating hydrometeors were provided by the 2DC probe and other in situ sensors onboard the ATR42 SAFIRE (7th FP EUFAR initiative - OSMOC project). We focus our attention on the final portion of the flight on 23 July 2007 when the aircraft was descending 


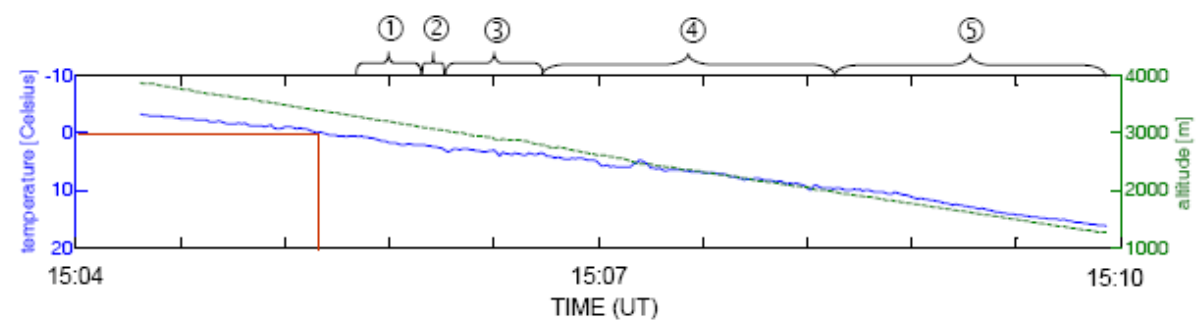

Fig. 10. Atmospheric temperature (blue line) and aircraft altitude (green line) in the time interval 15:04-15:10 UTC as measured by the insitu sensor (Gerber PMV100) on-board the ATR42 SAFIRE. The figure also identifies five distinct time intervals characterized by different precipitating particle types and properties, which are discussed in detail in Figs. 11 and 12.

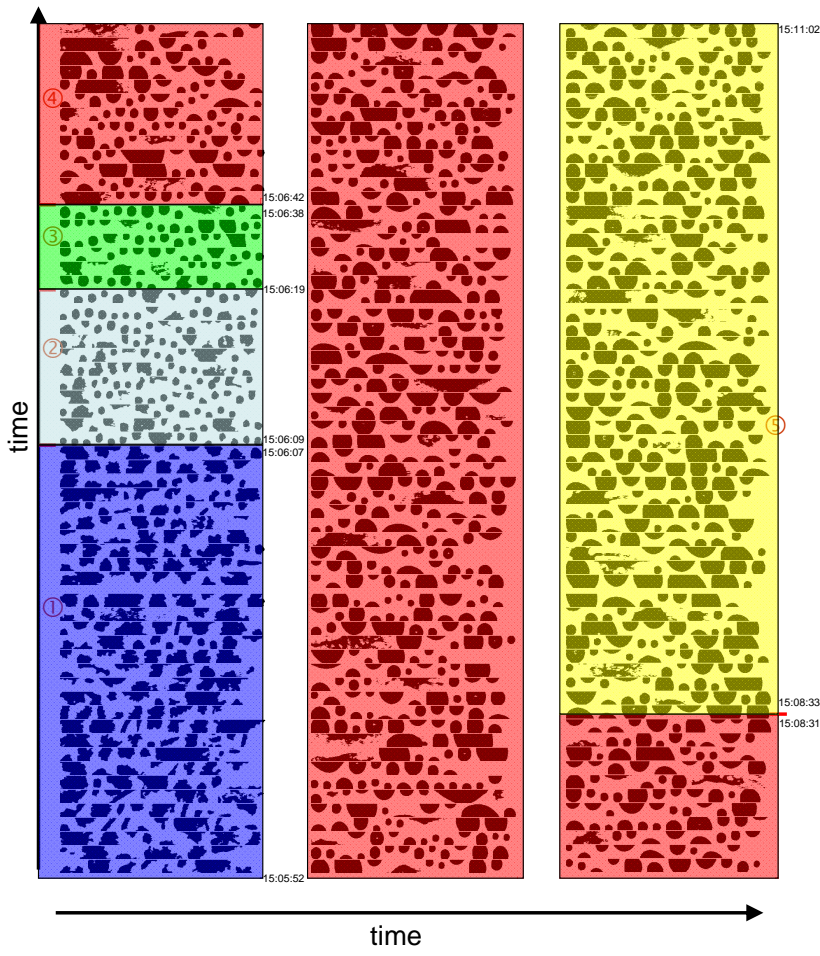

Fig. 11. Two-dimensional images of the melting hydrometeors probed by the in-situ 2DC probe on-board the ATR42 SAFIRE. The five distinct time intervals "1"- "5" are characterized by different precipitating particle types and properties.

through the melting layer. Figure 10 shows the time series of atmospheric temperature and aircraft altitude as measured in the time interval (15:04-15:10 UTC), with the melting level located around $3.35 \mathrm{~km}$ a.g.l. (same height as previously determined by the radiosonde).

The aircraft measurements were carried out approximately half an hour after the lidar measurements shown in Fig. 7 (as in fact no lidar measurements were possible after 14:35 UTC because of rain reaching the telescope) and the footprint of the aircraft is located at a distance of approximately 10$15 \mathrm{~km}$ from the lidar station. However, we believe that this time and space lag between the aircraft and the lidar mea- surements has minor effects on the comparison between measurements in the case of stratiform precipitation. In support to this, Figs. 2 and 3 reveal very limited variability of the radar reflectivity profiles at 1.29 and $35.5 \mathrm{GHz}$ in the one and half hour period (14:30-16:00 UTC) following the end of the lidar measurements, indicating a lack of local-scale meteorological variability during this period. The aircraft was moving along the Rhine Valley in the SouthEast-NorthWest direction and the aircraft - remote sensing site direction was parallel to the mountain ridges of the black forest. Orographic effects on both remote sensing and in-situ data are therefore expected to be marginal as both the ground site and aircraft were located over the same flat terrain with same weather situation undergone.

Figure 11 illustrates two-dimensional images of the melting hydrometeors resolved by the 2DC probe mounted below the aircraft wings. This figure reveals the progressive melting of the snowflakes and the reduction of particle size as a function of height, followed by an increase in size of the completely melted snowflakes (rain drops) most probably associated with the collision-coalescence process. Five distinct time intervals can be identified in Fig. 11, characterized by different precipitating particle types. Specifically, the time interval labelled as "1" (15:05:5-15:06:07, blue shadowed in the figure) identifies rimed aggregate snowflakes. Time interval "2" (15:06:09-15:06:19, light blue shadowed in the figure) is characterized by mixed rain drops with few rimed aggregates. The transition between time interval " 1 " and "2" depicts the structural collapse of melted snowflakes, conjectured by Sassen et al. (2005), taking place when water coatings accumulate on the ice crystal branches/sectors and inter-branch cavities of the shrinking particles. Time intervals "3"-"5" (interval "3", 15:06:19-15:06:38, green shadowed in the figure; interval "4", 15:06:42-15:08:31, red shadowed in the figure; interval " 5 "; 15:08:33-15:11:02, yellow shadowed in the figure) identify rain drops with progressively increasing size most probably as a result of the collision-coalescence process.

Results from the 2DC probe confirm the melting layer microphysical model proposed by Sassen et al. (2005) and document the structural collapse of melting snowflakes, playing 

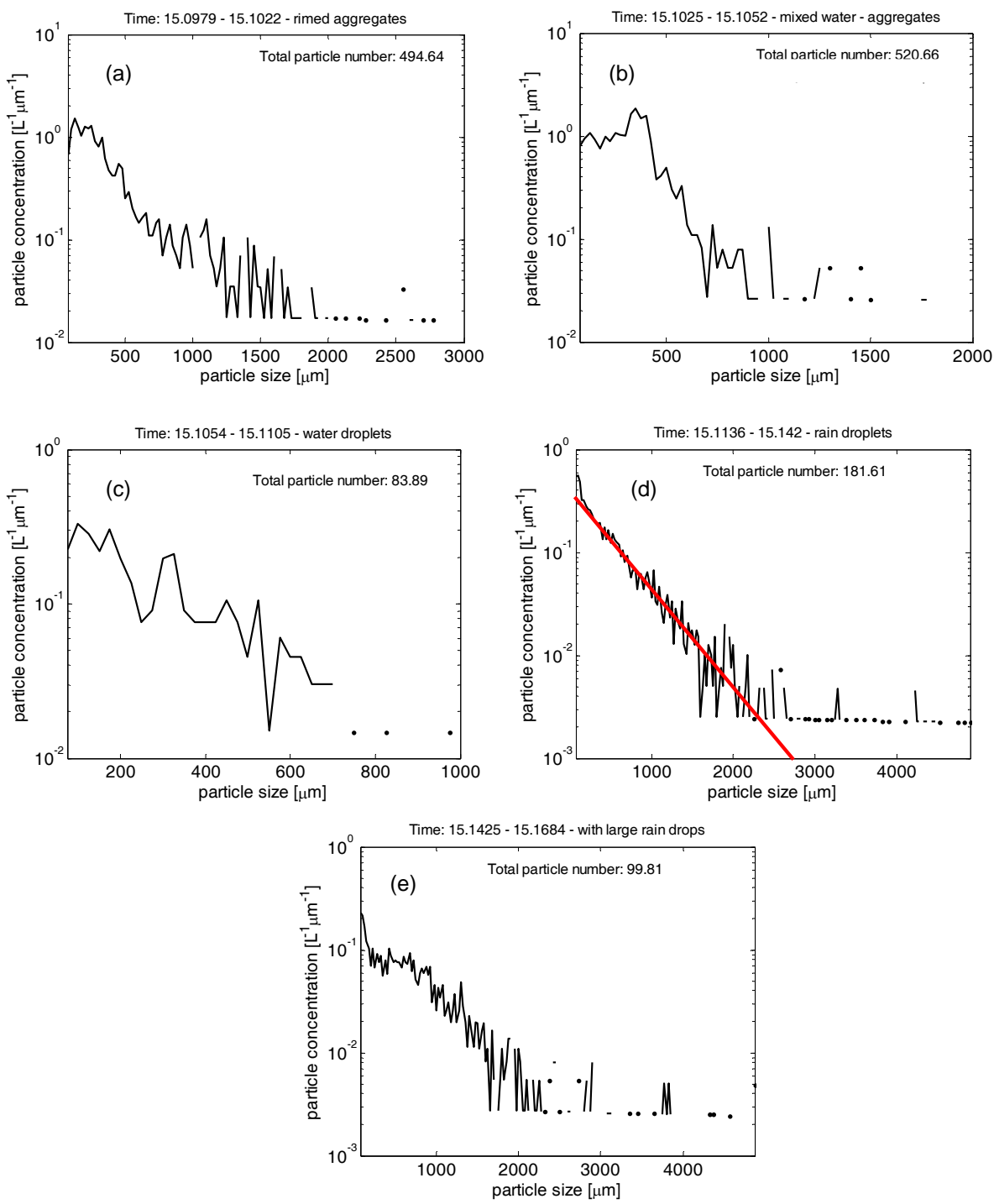

Fig. 12. Precipitating particle size distributions as obtained from the time series of the two-dimensional images. (a): time interval " 1 " (15:05:52-15:06:07), (b): time interval “2” (15:06:09-15:06:19), (c): time interval “3” (15:06:19-15:06:38), (d): time interval "4” (15:06:4215:08:31) and (e): time interval "5" (15:08:33-15:11:02).

a major role in the dark band phenomenon. Results are also compatible with the lidar depolarization measurements illustrated in the previous sections (i.e., characterized by low values in the melting region as a result of the melting particles turning into rain drops). Two-dimensional images of the melting hydrometeors in coincidence with the lidar bright and dark band measurements were also reported by Sassen and Chen (1995), documenting the presence of ice crystals and large snowflakes above the freezing level and high in the melting layer and the presence of raindrops from melting snowflakes below in the proximity of the lidar dark band.

Figure 12 illustrates the melting hydrometeor size distributions obtained from the time series of the two-dimensional images for the five distinct time intervals. In all panels, the number of particles decreases with increasing size.
Specifically, panel a shows the particle size distribution for the rimed aggregates in the time interval "1" (15:05:5215:06:07), with a total particle number concentration of $0.49464 \mathrm{~cm}^{-3}$. Panel $\mathrm{b}$ shows the particle size distribution for the mixed rain drops and rimed aggregates in the time interval "2" (15:06:09-15:06:19), with a total particle number concentration of $0.52066 \mathrm{~cm}^{-3}$. Panels c-e illustrate the particle size distribution for rain drops, with total particle number concentration being $0.08389 \mathrm{~cm}^{-3}, 0.18161 \mathrm{~cm}^{-3}$ and $0.09981 \mathrm{~cm}^{-3}$, respectively.

A Marshall and Palmer size distribution has been used to fit the data points in Fig. 12a-e, expressed as:

$n(D)=n_{0} \exp (-\Lambda D)$ 


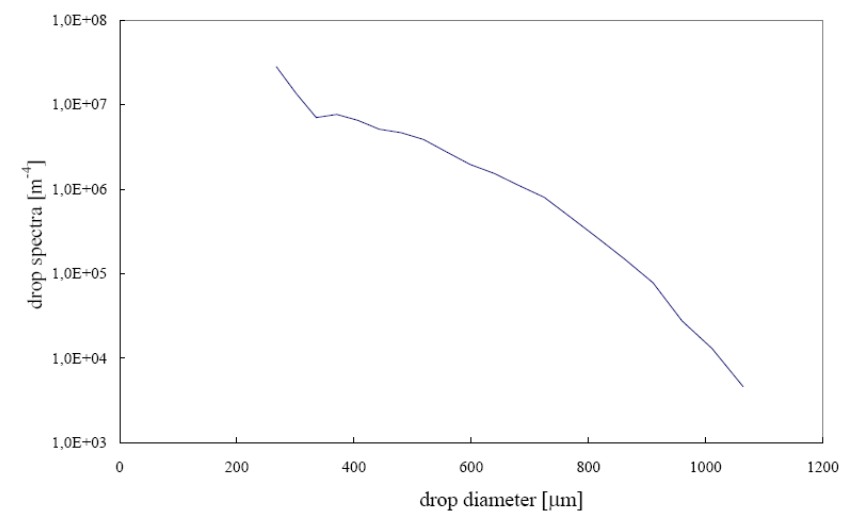

Fig. 13. Particle size spectrum as obtained from the rain radar.

with the mean diameter, $D_{0}$, being equal to $1 / \Lambda$ (Pruppacher and Klett, 1997). As particle concentrations are displayed in Fig. 12a-e in semi-log scale, for fitting purposes expression (1) can be reformulated as:

$\log n(D)=\log n_{0}-\Lambda D$

Values of $\Lambda$, and consequently of $D_{0}$, for the different panels in Fig. 12 can be obtained by the linear regression of the data points in these panels, with $\Lambda$ being the slope of the fitting line. To avoid overloading of the figures, the fitting line is shown only in Fig. 12d. Values of $D_{0}$ obtained from the fitting procedure are found to be $348,305,278,421$ and $654 \mu \mathrm{m}$ for the time intervals "1", "2", "3", "4" and "5", respectively. These results once again indicate that melting hydrometers progressively decrease in size during the melting process till they become raindrops (intervals " 1 " through "3"). Afterwards, they progressively increase in size, most probably as a result of the collision-coalescence process (intervals " 3 " through " 5 ").

Figure 13 illustrates the precipitating particle size spectrum at $2 \mathrm{~km}$ a.g.l. obtained from the rain radar at $24.15 \mathrm{GHz}$. At this altitude, precipitating particles are expected to be primarily rain drops. The particle size spectrum in this figure is in good agreement with the measurements performed by the 2DC probe, again revealing a size spectrum characterized by values decreasing with increasing size. As for the data points in Fig. 12, the data points in Fig. 13 have been least-squared fitted through the Marshall and Palmer size distribution function given in expression (1), leading to a mean diameter $D_{0}=190 \mu \mathrm{m}$, which once again is in general agreement with the values of $\mathrm{D}_{0}$ provided by the $2 \mathrm{DC}$ probe $(278$, 421 and $654 \mu \mathrm{m}$ for the time intervals " 3 ", " 4 " and "5", respectively).

Finally, Fig. 14 illustrates the size distribution of the precipitating particles obtained from the disdrometer highresolution (1 $\mathrm{min})$ rainfall-rate measurements performed at ground level at Besenfeld, $27 \mathrm{~km}$ East of Supersite R. The disdrometer data were collected at 14:59-15:04, approximately 25 min after the lidar and radar data in Fig. 7. Fig-

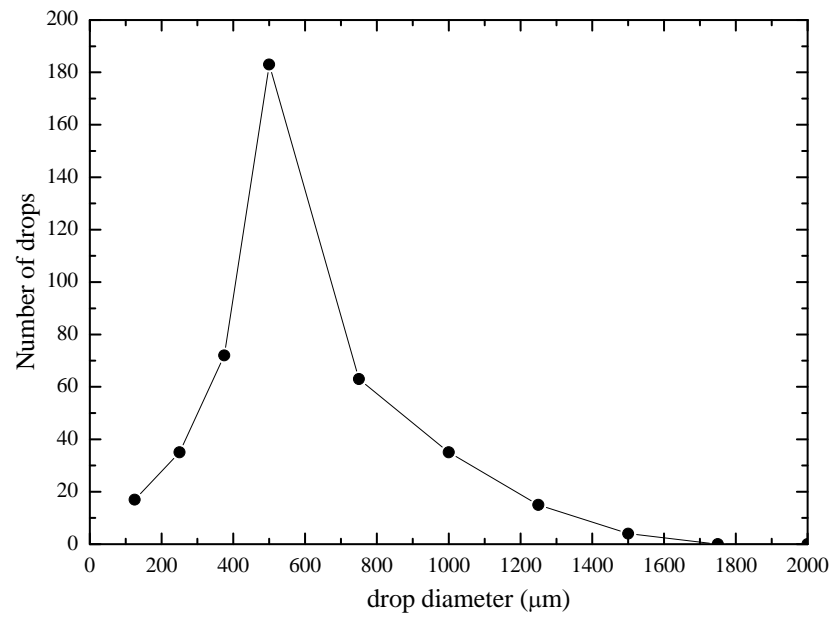

Fig. 14. Precipitating particle size distribution as obtained from the time series of the disdrometer measurements at ground level in Besenfeld ( $27 \mathrm{~km}$ East of Supersite R).

ure 14 reveals the presence of rain drops with a mean particle diameter of $450 \mu \mathrm{m}$, in good agreement with those provided by the 2DC probe. Results in Fig. 14 also reveal the presence of a reduced number of particles smaller than $450 \mu \mathrm{m}$, which were otherwise detected in large concentrations in the measurements aloft by both the 2DC probe and the rain radar. In this respect, it should be noted that rain measurements at the surface can substantially differ from conditions aloft in the melting region (2-3 km in our case) because of the temporal variations in the convective showers and the predominant role of coalescence in homogenizing the drop size spectrum.

\section{Summary and future work}

This paper reports observations of the melting layer based on the synergetic use of a variety of sensors, which includes a Raman lidar providing multi-wavelength backscatter, extinction and depolarization measurements, three radar systems providing multi-wavelength radar reflectivity, depolarization and Doppler velocity measurements, a high-resolution disdrometer and a two-dimensional cloud (2DC) probe hosted on-board the ATR42, with ancillary information on the state of the atmosphere provided by radiosondes launched from a co-located radiosonde station. The measurements were carried out in Achern (Rhine Valley, Southern Germany) in the frame of the COPS - Convective and Orographically-induced Precipitation Study.

Measurements reported in this paper focus on a case study (23 July 2007) characterized by a reduced precipitation intensity, revealing the presence of the full repertoire of the dark/bright band phenomena in lidar (backscatter/depolarization) and radar (reflectivity, Doppler velocity, depolarization) measurements. Specifically, a maximum in radar reflectivity is found at $35.5 \mathrm{GHz}, 24.15 \mathrm{GHz}$ and 
$1.29 \mathrm{GHz}$, located approximately $350-450 \mathrm{~m}$ below the melting level (at temperatures of $3.4-4.4{ }^{\circ} \mathrm{C}$ ), the maximum being less marked at $35.5 \mathrm{GHz}$ because of the dominance at shorter wavelengths of non-Rayleigh scattering effects in large water-coated snowflakes. Lidar measurements of particle backscattering at 355, 532 and $1064 \mathrm{~nm}$ reveal the presence of a minimum (lidar dark band) approximately 450 $\mathrm{m}$ below the melting level (at a temperature of $4.4{ }^{\circ} \mathrm{C}$ ), as well as the presence of two maxima (lidar bright bands), one more marked located in the proximity of the melting level and one weaker located $100-200 \mathrm{~m}$ below the dark band. The distance of the weaker bright band from the melting level and the vertical extent of this band are strongly dependent on the hydrometeor size, but are also influenced by the precipitation rate and by the presence of particle evaporation/sublimation mechanisms. The stronger lidar bright band displays a wavelength dependent behaviour with a more marked presence at 532 and $1064 \mathrm{~nm}$ than at $355 \mathrm{~nm}$ because of the more pronounced attenuation of the laser beam through the snow at the former wavelengths. On the contrary, the particle backscatter profiles reveal a very limited wavelength dependence of the dark and weak bright band features, not unexpectedly indicating that the sounded particles are much larger than the sounding wavelength and behave as geometric optics scatters.

Radar depolarization shows a maximum corresponding with the height of the radar bright band, while lidar depolarization shows low values (5-10\%) at the heights of the lidar dark and bright bands, which may imply that the profiled precipitating particles were severely melted snowflakes collapsing into mixed phase particles and thus exhibiting a more regular shape. Particle vertical velocities display an abrupt increase within the melting layer, with values of $2-2.5 \mathrm{~m} \mathrm{~s}^{-1}$ high in the melting layer and values of $3.5-4 \mathrm{~m} \mathrm{~s}^{-1}$ in the lower portion of the melting layer. Values measured by the rain radar at $24.15 \mathrm{GHz}$ show slightly larger values both in the upper melting layer and in the lower portion of the melting layer, probably as a result of the higher sensitivity of the $24.15 \mathrm{GHz}$ band to larger and consequently faster particles.

The results reported here are in good agreement with previous lidar/radar observations from Sassen and Chen (1995), Demoz et al. (2000) and Sassen et al. (2005) and confirm and support the microphysical/scattering model interpretation of the melting layer phenomena conceived by Sassen et al. (2005). The present measurements were carried out in very light precipitation conditions, characterized by rainfall rates $\left(0.02-0.05 \mathrm{~mm} \mathrm{~h}^{-1}\right)$ a factor of $\sim 2$ smaller than those reported by Sassen et al. (2005) for their light intensity rain shower cases, thus complementing the measurement scenarios reported by these authors.

The lidar dark and bright bands were simulated with the use of concentric/eccentric sphere Lorentz-Mie codes and a melting layer model. Model runs were able to simulate the lidar dark band arising below the melting level as a result of the progression of the snow-flake melting and determin- ing an abrupt increase in lidar backscattering when melting ratio values are in the range of $0.5-0.8$. The present model results are not wholly considered representative because of the limitations of the simplified representation of the melting hydrometeors (two-layered concentric-eccentric sphere particles) considered in the computations. A more realistic approach would consist in the application of a Monte Carlo ray-tracing model based on geometrical optics methods. Additionally, as properly pointed out by Sassen et al. (2005), different types of mixed-phase particles may be profiled in the melting layer and the exact nature of the particles undergoing the phase change, including their density, size distribution, and amount of riming, will affect the particle backscattering and velocity outcomes within the melting layer and influence the exact interrelationships between the various lidar and radar melting layer features.

Lidar and radar measurements and model results have been compared with measurements from a 2DC probe onboard the ATR42 SAFIRE. Two-dimensional images of the hydrometeors descending through the melting layer reveal the progressive melting and reduction of size of the snowflakes till they become raindrops, which is followed by an increase in size of the raindrops most likely associated with the collision-coalescence process. These results are compatible with the considered model interpretation and with the reported lidar and radar measurements, both in terms of backscatter/reflectivity and depolarization. The size distributions of melting hydrometeors obtained from the time series of the two-dimensional images have been fitted by a Marshall and Palmer function, leading to estimates of the melting hydrometeor diameters (in the range 300-650 $\mu \mathrm{m}$ ) in agreement with measurements from the rain radar and a disdrometer on ground.

As a continuation of this study, we plan to extend the present analysis to all available dark/bright band case studies observed during COPS, covering the full ensemble of precipitation conditions and rates encountered during the field effort. We also plan to test the application of an inversion algorithm to retrieve the precipitating particle size and microphysical parameters from the multi-wavelength lidar data of particle backscattering, extinction and depolarization, based on the use of a Mie scattering code and a retrieval scheme employing Tikhonov's inversion with regularization. More experimental data for a comprehensive understanding of melting layer phenomena are expected to be obtained from scanning dual-polarization lidar measurements, which were not available during COPS but are planned to be implemented in the future, as in fact inhomogeneous melting drops tend to orientate, so that a lidar elevation angle dependence of return signals may be present. 


\section{Appendix A}

The two-dimensional cloud (2DC) probe is mounted below the aircraft wings on-board the scientifically equipped ATR42 from Service des Avions Français Instrumentés pour la Recherche en Environnement. It provides two-dimensional images of the atmospheric particles, with a maximum detectable particle size of $2 \mathrm{~mm}$. Measurements can be used to retrieve cloud and precipitating particle size distribution. An additional collocated sensor (Gerber PMV100) provides time series measurements of the aircraft altitude, atmospheric temperature and LWC. The 2DC probe is composed of two separate parallel branches: a linear array of 30 photodiodes ( $25 \mu \mathrm{m}$ diameter each, with a total length of $800 \mu \mathrm{m}$ ) is located along one branch, while a diode laser illuminating the array of photodiodes is located along the opposite branch. The array is oriented perpendicular to the airflow, so that any time a particle passes in between the two branches, a certain number of photodiodes are shadowed, producing a line of black points. By sampling at an high rate of $10 \mathrm{~Hz}$, the sequence of lines produces a two-dimensional image of the particles passing through the branches. The particles images in the Fig. 11 are the representation of this time series of shadowed lines.

Acknowledgements. This work was supported by the European Commission under the European Fleet for Airborne Research program of the 7th Framework Program (Projects H2OLidar and OSMOC). We also wish to thank the International Science Steering Committee of the Convective and Orographically-induced Precipitation Study for financial supporting this activity. We wish to thank the University of Innsbruck for the provision of the disdrometer data. The participation of M. Cacciani to this work was supported through the project PRIN 2007L8Y4NB funded by the Italian Ministry for University and Research, MIUR.

Edited by: B. Mayer

\section{References}

Aden, Q. L. and M. Kerker, Scattering of Electromagnetic Waves from Two Concentric Spheres, J. Appl. Phys., 22, 1242-1246, 1951.

Aydin, K., and Y. Zhao, A computational Study of Polarimetric Radar Observables in Hail, IEEE Trans. Geosci. Remote Sens., 28, 412- 422, 1990.

Battan, L. J.: Radar Observations of the Atmosphere, Univ. of Chicago Press, USA, 279 pp., 1973,

Bhawar, R., Di Girolamo, P., Summa, D., Flamant, C., Althausen, D., Behrendt, A., Kiemle, C., Bosser, P., Cacciani, M., Champollion, C., Di Iorio, T., Engelmann, R., Herold, C., Müller, D., Pal, S., Wirth, M., and Wulfmeyer, V.: The Water Vapour Intercomparison Effort in the Framework of the Convective and Orographically-Induced Precipitation Study: Airborne-to-
Ground-based and airborne-to-airborne Lidar Systems, Q. J. Roy. Meteorol. Soc. , 137, 325-348, doi:10.1002/qj.697, 2011.

Behrendt, A., Pal, S., Aoshima, F., Bender, M., Blyth, A., Corsmeier, U., Cuesta, J., Dick, G., Dorninger, M., Flamant, C., Di Girolamo, P., Gorgas, T., Huang, Y., Kalthoff, N., Khodayar, S., Mannstein, H., and Wulfmeyer V.: Observation of Convection Initiation Processes with a Suite of State-of-the-Art Research Instruments during COPS IOP8b, Q. J. Roy. Meteorol. Soc. , 137, 81-100, doi:10.1002/qj.758, 2011.

Bennett, L. J., Blyth, A. M., Burton, R. R., Gadian, A. M., Weckwerth, T. M., Behrendt, A., Di Girolamo, P., Dorninger, M., Lock, S.-J., Smith, V. H., and Mobbs, S. D.: Initiation of convection over the Black Forest mountains during COPS IOP15a, Q. J. Roy. Meteorol. Soc. , 137, 176-189, doi:10.1002/qj.760, 2011.

Chaboureau, J.-P., Richard, E., Pinty, J.-P., Flamant, C., Di Girolamo, P., Kiemle, C., Behrendt, A., Chepfer, H., Chiriaco, M., and Wulfmeyer, V.: Long-range transport of Saharan dust and its impact on precipitation forecast: A case study during the Convective and Orographically-Induced Precipitation Study, Q. J. Roy. Meteorol. Soc., 137, 236-251, doi:10.1002/qj.719, 2011.

Corsmeier, U., Kalthoff, N., Barthlott, C., Aoshima, F., Behrendt, A., Di Girolamo, P., Dorninger, M., Handwerker, J., Kottmeier, C., Mahlke, H., Mobbs, S. D., Norton, E. G., Wickert, J., and Wulfmeyer, V.: Processes driving deep convection over complex terrain: A multi-scale analysis of observations from COPS-IOP9c, Q. J. Roy. Meteorol. Soc., 137, 137-155, doi:10.1002/qj.754, 2011.

Demoz, B. B., Starr, D., Whiteman, D., Evans, K., Hlavka, D., and Peravali, R.: Raman LIDAR Detection of Cloud Base, Geophys. Res. Lett., 27, 1899-1902, 2000.

Di Girolamo P., Pappalardo, G., Spinelli, N., Berardi, V., and Velotta, R.: Lidar Observations of the stratospheric aerosol layer over Southern Italy in the period 1991-1995, J. Geophys. Res., 101, 18765-18773, doi:10.1029/96JD01172, 1996.

Di Girolamo P., Ambrico, P. F., Amodeo, A., Boselli, A., Pappalardo, G., and Spinelli, N.: Aerosol observations by lidar in the Nocturnal Boundary Layer, Appl. Opt., 38, 4585-4595, doi:10.1364/AO.38.004585, 1999.

Di Girolamo, P., Demoz, B. B., and Whiteman, D. N.: Model simulations of melting hydrometeors: A new lidar bright band from melting frozen drops, Geophys. Res. Lett., 30, 1626, doi:10.1029/2002GL016825, 2003.

Di Girolamo, P., Marchese, R., Whiteman, D. N., and Demoz, B. B.: Rotational Raman Lidar measurements of atmospheric temperature in the UV, Geophys. Res. Lett., 31, L01106, doi:10.1029/2003GL018342, 2004.

Di Girolamo, P., Behrendt, A., and Wulfmeyer, V.: Spaceborne profiling of atmospheric temperature and particle extinction with pure rotational Raman lidar and of relative humidity in combination with differential absorption lidar: performance simulations, Appl. Opt., 45, 2474-2494, doi:10.1364/AO.45.002474, 2006.

Di Girolamo, P., Summa, D., and Ferretti, R.: Multiparameter Raman Lidar Measurements for the Characterization of a Dry Stratospheric Intrusion Event, J. Atmos. Ocean. Tech. , 26, 17421762, doi:10.1175/2009JTECHA1253.1, 2009a.

Di Girolamo, P., Summa, D., Lin, R.-F., Maestri, T., Rizzi, R., and Masiello, G.: UV Raman lidar measurements of relative humidity for the characterization of cirrus cloud microphysical properties, Atmos. Chem. Phys., 9, 8799-8811, doi:10.5194/acp-9- 
8799-2009, 2009b.

Di Girolamo, P., Summa, D., Bhawar, R., Di Iorio, T., Cacciani, M., Veselovskii, I., Dubovik, O., and Kolgotin, A.: Raman lidar observations of a Saharan dust outbreak event: characterization of the dust optical properties and determination of particle size and microphysical parameters, Atmos. Environ., 50, 66-78, doi:10.1016/j.atmosenv.2011.12.061, 2012.

Fabry, F. and Szyrmer, W.: Modelling of the Melting Layer, Part II: Electromagnetic, J. Atmos. Sci., 56, 3539-3600, 1999.

Griaznov, V., Veselovskii, I., Di Girolamo, P., Demoz, B., and Whiteman, D. N.: Numerical Simulation of Light Backscattering by Spheres With Off-Center Inclusion. Application for the Lidar Case, Appl. Optics, 43, 5512-5522, doi:10.1364/AO.43.005512, 2004.

Griaznov, V., Veselovskii, I., Di Girolamo, P., Korenskii, M., and Summa, D.: Spatial distribution of doubly scattered polarized laser radiation in the focal plane of a lidar receiver, Appl. Opt. , 46, 6821-6830, doi:10.1364/AO.46.006821, 2007.

Irvine, W. M. and Pollack, J. B.: Infrared optical properties of water and Ice spheres, Icarus, 8, 324-360, 1968.

Kalthoff, N., Adler, B., Barthlott, C., Corsmeier, U., Mobbs, S., Crewell, S., Trumner, K., Kottmeier, C., Wieser, A., Smith, V., and Di Girolamo, P.: The impact of convergence zones on the initiation of deep convection: a case study from COPS, Atmos. Res., 93, 680-694, doi:10.1016/j.atmosres.2009.02.010, 2009.

Kiemle, C., Wirth, M., Fix, A., Rahm, S., Corsmeier, U., and Di Girolamo, P.: Latent Heat Flux Measurements over Complex Terrain from Airborne Water Vapour and Wind Lidars, Q. J. Roy. Meteorol. Soc. , 137, 204-223, doi:10.1002/qj.757, 2011.

Kiran Kumar, N. V. P., Narayana Rao, T., Narayana Rao, D., and Kunhikrishnan, P. K.: Studies of radar bright band using UHF radar at Gadanki, Proc. SPIE, 6408, 64081J, doi:10.1117/12.694120, 2006.

Kottmeier, C., Kalthoff, N., Barthlott, C., Corsmeier, U., Van Baelen, J., Behrendt, A., Behrendt, R., Blyth, A., Coulter, R., Crewell, S., Di Girolamo, P., Dorninger, M., Flamant, C., Foken, T., Hagen, M., Hauck, C., Höller, H., Konow, H., Kunz, M., Mahlke, H., Mobbs, S., Richard, E., Steinacker, R., Weckwerth, T., Wieser, A., and Wulfmeyer, V.: Mechanisms initiating deep convection over complex terrain during COPS, Meteorol. Z. , 17, 931-948, 2008.

Lhermitte, R.: Observation of rain at vertical incidence with a $94 \mathrm{GHz}$ Doppler radar: An insight on Mie scattering, Geophys.Res. Lett., 15, 1125-1128, 1988.

Lhermitte, R.: Centimeter and Millimeter Wavelength Radars in Meteorology, Lhermitte Productions, 550 pp., 2002.

Maestri, T., Di Girolamo, P., Summa, D., and Rizzi, R.: Clear and cloudy sky investigations using Raman lidar and airborne interferometric measures from the European AQUA Thermodynamic Experiment, Italy 2004, Atmos. Res., 97, 157-169, doi:10.1016/j.atmosres.2010.03.020, 2010.

Matrosov, S. Y., Kingsmill, D. E., Martner, B. E., and Ralph, F. M.: The Utility of X-Band Polarimetric Radar for Quantitative Estimates of Rainfall Parameters, J. Hydrometeorol., 6, 248-262, 2005.

Meneghini, R. and Liao, L.: Effective Dielectric Constants of Mixed-Phase Hydrometeors, J. Atmos. Ocean. Tech. , 17, 628$640,2000$.
Mitra, S. K., O. Vohl, M. Ahrand, and H. R. Pruppacher, Awind tunnel and theoretical study of the melting behavior of atmospheric ice particles, IV: Experiment and theory for snow flakes, J. Atmos. Sci., 47, 584-591, 1990.

Norton, E. G., Vaughan, G., Methven, J., Coe, H., Brooks, B., Gallagher, M., and Longley, I.: Boundary layer structure and decoupling from synoptic scale flow during NAMBLEX, Atmos. Chem. Phys., 6, 433-445, doi:10.5194/acp-6-433-2006, 2006.

Prodi, F., Moretti, A., Sturniolo, O.: Backscattering Gain Measurements of Spherical Ice Hydrometeors at $35.8 \mathrm{GHz}$ and Comparison to Numerical Computations, J. Atmos. Ocean. Technol., 13, 407-418, 1996.

Pruppacher, H. and Beard, K. V.: A wind tunnel investigation of the internal circulation and shape of water drops falling at terminal velocity in air, Q. J. Roy. Meteorol. Soc. , 96, 247-256, 1970.

Pruppacher, H. R. and Klett, J. D.: Microphysics of clouds and precipitation, Kluwer Academic Publishers, Dordrecht and Boston, 954 pp., 1997.

Rasmussen, R. M., Levizzani, V., and Pruppacher, H. R.: A wind tunnel and theoretical study on the melting behavior of atmospheric ice particles. II:a theoretical study for frozen drops of radius $<500$ m. J. Atmos. Sci. , 41, 374-380, 1984.

Richard, E., Flamant, C., Bouttier, F., Van Baelen, J., Champollion, C., Hagen, M., Cuesta, J., Bosser, P., Pigeon, G., Argence, S., Arnault, J., Brousseau, P., Seity, Y., Chaboureau, J.-P., Limnaios, P., Masson, F., Pointin, Y., Di Girolamo, P., and Wulfmeyer, V.: La campagne COPS : Initiation et cycle de vie de la convection en région montagneuse, La Météorologie, 64, 32-42, 2009.

Rogers, R. R. and Yau, M. K.: A Short Course in Cloud Physics, Third Ed., International Series in Natural Philosophy, Ed. Butterworth and Heinemann, 1989.

Roy, G. and Bissonnette, L. R.: Strong dependence of rain-induced lidar depolarization on the illumination angle: Experimental evidence and geometrical- optics interpretation, Appl. Opt., 40, 4770-4780, 2001.

Sassen, K.: Laser depolarization "bright band" from melting snowflakes, Nature, 255, 316-318, 1975.

Sassen, K.: Lidar observations of high plains thunderstorm precipitation, J. Atmos. Sci., 34, 1444-1457, 1977a.

Sassen, K.: Optical backscattering from near-spherical water, ice, and mixed phase drops, Appl. Opt., 16, 1332-1341, $1977 \mathrm{~b}$.

Sassen, K. and Chen, T.: The lidar dark band: An oddity of the radar bright band, Geophys. Res. Lett. , 22, 3505-3508, 1995.

Sassen, K., DeMott, P. J., Prospero, J. M., and Poellot, M. R.: Saharan dust storms and indirect aerosol effects on clouds: CRYSTAL-FACE results, Geophys. Res. Lett., 30, 1633, doi:10.1029/2003GL017371, 2003.

Sassen, K., Campbell, J. R., Zhu, J., Kollias, P., Shupe, M., and Williams, C.: Lidar and triple-wavelength Doppler radar measurements of the melting layer: A revised model for dark and bright band phenomena, J. Appl. Meteor. , 44, 301-312, 2005.

Sassen, K., Matrosov, S., and Campbell, J.: CloudSat spaceborne $94 \mathrm{GHz}$ radar bright bands in the melting layer: An attenuationdriven upside-down lidar analog, Geophys. Res. Lett., 34, L16818, doi:10.1029/2007GL030291, 2007.

Smith, T. J. and Illingworth, A. J.: Radar estimates of rainfall rates at the ground in bright band and non-bright band events, Q. J. Roy. Meteorol. Soc., 124, 2417-2434, 1998. 
Stewart, R. E., Marwitz, J. D., Pace, J. C., and Carbone, R. E.: Characteristics through the melting layer of stratiform clouds, J. Atmos. Sci., 41, 3227-3237, 1984.

Toon, O. B. and Ackerman, T. P.: Algorithms for calculation of scattering by stratified spheres, Appl. Opt., 20, 3657-3660, 1981.

Yokoyama, T. and Tanaka, H.: Microphysical processes of melting snowflakes detected by two-wavelength radar. Part I. Principle of measurement based on model calculation, J. Meteorol. Soc. Jpn., 62, 650-666, 1984.

Wexler, R.: The melting layer, Blue Hill Obs., Harvard Univ., Meteorol. Radar Studies, No. 3., 1955.

Wulfmeyer, V., Behrendt, A., Bauer, H. S., Kottmeier, C., Corsmeier, U., Blyth, A., Craig, G., Schumann, U., Hagen, M., Crewell, S., Di Girolamo, P., Flamant, C., Miller, M., Montani, A., Mobbs, S., Richard, E., Rotach, M. W., Arpagaus, M., Russchenberg, H., Schlüssel, P., König, M., Gärtner, V., Steinacker, R., Dorninger, M., Turner, D. D., Weckwerth, T., Hense, A., and Simmer, C.: The convective and orographically-induced precipitation study: A research and development project of the World Weather Research Program for Improving Quantitative Precipitation Forecasting in Low-mountain Regions, B. Am. Meteor. Soc., 89, 1477-1486, doi:10.1175/2008BAMS2367.1, 2008.
Wulfmeyer, V., Behrendt, A., Kottmeier, C., Corsmeier, U., Barthlott, C., Craig, G. C., Hagen, M., Althausen, D., Aoshima, F., Arpagaus, M., Bauer, H. S., Bennett, L., Blyth, A., Brandau, C., Champollion, C., Crewell, S., Dick, G., Di Girolamo, P., Dorninger, M., Dufournet, Y., Eigenmann, R., Engelmann, R., Flamant, C., Foken, T., Gorgas, T., Grzeschik, M., Handwerker, J., Hauck, C., Höller, H., Junkermann, W., Kalthoff, N., Kiemle, C., Klink, S., König, M., Krauss, L., Long, C. N., Madonna, F., Mobbs, S., Neininger, B., Pal, S., Peters, G., Pigeon, G., Richard, E., Rotach, M. W., Russchenberg, H., Schwitalla, T., Smith, V., Steinacker, R., Trentmann, J., Turner, D. D., van Baelen, J., Vogt, S., Volkert, H., Weckwerth, T., Wernli, H., Wieser, A., and Wirth, M.: The Convective and Orographically-Induced Precipitation Study (COPS): The Scientific Strategy, the Field Phase, and Research Highlights, Q. J. Roy. Meteorol. Soc., 137, 3-30, doi:10.1002/qj.752, 2011. 